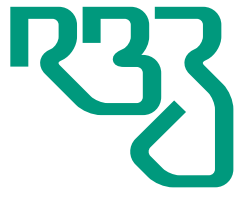

Revista Brasileira de Zootecnia

Brazilian Journal of Animal Science ISSN 1806-9290 www.rbz.org.br

\section{Use of conjugated linoleic acid (trans 10, cis 12) to cultivate bovine embryos: effect on cryoresistance and lipid content}

\author{
Bruno Pena Carvalho ${ }^{1,2^{*}}$ (iD), Fernanda de Queirós Costa ${ }^{1}$, Danielly Detoni ${ }^{1}$, \\ Felipe Borges Rosa ${ }^{1}$, Angelo José Burla Dias ${ }^{1}$ (iD \\ ${ }^{1}$ Universidade Estadual do Norte Fluminense Darcy Ribeiro, Campos dos Goytacazes, \\ $\mathrm{RJ}$, Brasil. \\ ${ }^{2}$ Empresa Brasileira de Pesquisa Agropecuária, Rio Branco, AC, Brasil.
}

*Corresponding author: bruno.pena@embrapa.br

Received: January 17, 2019

Accepted: July 14, 2019

How to cite: Carvalho, B. P.; Costa, F. Q.; Detoni, D.; Rosa, F. B. and Dias, A. J. B. 2019. Use of conjugated linoleic acid (trans 10, cis 12) to cultivate bovine embryos: effect on cryoresistance and lipid content. Revista Brasileira de Zootecnia 48:e20180322. https://doi.org/10.1590/rbz4820180322

Copyright: This is an open access article distributed under the terms of the

Creative Commons Attribution License (http://creativecommons.org/licenses/by/4.0/), which permits unrestricted use, distribution, and reproduction in any medium, provided the original work is properly cited.

\begin{abstract}
This study evaluated the effect of the addition of conjugated linoleic acid (CLA) to in vitro culture on viability, lipid content, and cryoresistance of bovine embryos at different in vitro culture times. Cumulus oocyte complexes $(\mathrm{N}=974)$ were maturated in vitro for $22 \mathrm{~h}$. In vitro fecundation ensued for $18 \mathrm{~h}$. Viable zygotes were cultivated in vitro in medium supplemented with CLA $(100 \mathrm{mM})$ in the first $72 \mathrm{~h}$ (CLA-F), last $72 \mathrm{~h}$ (CLA-L), or throughout the culture period (CLA-T). Control embryos (control) were cultivated with no CLA. Embryos were cryopreserved by vitrification for subsequent analysis after devitrification. Effect of CLA on cryoresistance was assessed by cultivating embryos in synthetic oviductal fluid containing 5\% fetal bovine serum. Lipid content was quantified using Nile Red staining. No significant difference was observed in cleavage rate, blastocyst:total oocyte ratio, and blastocyst:cleaved oocyte ratio. Culture in CLA-L reduced survival rate $24 \mathrm{~h}$ after devitrification compared with CLA-F and CLA-T, although with no statistically significant difference compared with control group. However, CLA-T improved embryo hatching rate and affected lipid content of embryos. Cultures CLA-F and CLA-L increased lipid content compared with control. Yet, lipid content values decreased in embryos treated with CLA-T, but they did not differ significantly from the values observed for oocytes at the germinal vesicle stage. Treatment of bovine embryos with CLA during in vitro cultivation did not affect the production of blastocysts, reducing lipid content and improving cryoresistance. However, the effects of CLA on cryoresistance and lipid content is significant only when embryos are exposed to the compound throughout the cultivation period.
\end{abstract}

Keywords: cryotolerance, polyunsaturated fatty acid, vitrification

\title{
Introduction
}

In vitro embryos are more sensitive to freezing than in vivo embryos and have low hatching rates after devitrification (Sudano et al., 2011). The main reason behind the poor freezability of in vitro embryos is the high lipid contents (Rizos et al., 2003; Seidel Jr., 2006; Barceló-Fimbres and Seidel Jr., 2011). Among the main factors identified as responsible for the increase of lipid content in in vitro-produced embryos is the addition of fetal calf serum (FCS) in culture media (Seidel Jr., 2006; Lapa et al., 2011; Sudano et al., 2011). Fetal calf serum may contain factors that stimulate the production of lipogenic enzymes (Barceló-Fimbres and Seidel Jr., 2007), and the activity of the lipogenic metabolic pathway may increase due to the high levels of glycose in FCS (Rizos et al., 2003), and this may result in changes in the energy metabolism. 
Mammal preimplantation embryos undergoes a marked change in energy metabolism during embryo genome activation. Until the 8- to-16 cell stage, embryos use essentially pyruvate as energy source. After compaction, glycose consumption increases sharply (Khurana and Niemann, 2000). In in vitro bovine embryos, the 8- to-16 cell stage starts about $96 \mathrm{~h}$ after fertilization, or $72 \mathrm{~h}$ into cultivation (Leidenfrost et al., 2011).

This marked change in this specific period has led to the proposition of sequential culture media, in which factors are added or withdrawn according to the moment of embryo development (Wrenzycki, 2016).

To reduce lipid levels and improve cryoresistance of in vitro embryos, polyunsaturated fatty acids, like conjugated linoleic acid (CLA; trans 10, cis 12), have been added to culture media (Pereira et al., 2007; Al Darwich et al., 2010; Stinshoff et al., 2014; Absalón-Medina et al., 2014; Batista et al., 2014; Leão et al., 2015). Conjugated linoleic acid changes the fatty acids profile during maturation, inhibiting the expression of genes that code for lipogenic enzymes and reducing lipid content, while cryoresistance improves, especially when media containing FCS are used (Lee et al., 1998; Baumgard et al., 2002; Pereira et al., 2007; Al Darwich et al., 2010).

Thus, the objective of the present study was to evaluate the effect of the supplementation with CLA at different times of the embryo in vitro cultivation (pre- and post-compaction). To this end, embryo production, lipid content, and cryoresistance were analyzed in a production model using bovine fetal serum.

\section{Material and Methods}

All stages of the present study were carried out in the city of Campos dos Goytacazes, Rio de Janeiro,

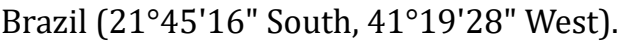

Embryos were produced according to Pontes et al. (2011) with adaptations. Briefly, cumulus oophorus complexes (COC) aspired from ovaries collected from female bovines in a local slaughterhouse were used. The COC were transported to the laboratory in sterile saline ( $\mathrm{NaCl} 0.9 \%$ ) supplemented with antibiotics (penicillin $100 \mathrm{IU} \mathrm{mL}^{-1}$ and streptomycin $100 \mu \mathrm{g} \mathrm{mL}^{-1}$ ) at approximately $25{ }^{\circ} \mathrm{C}$ throughout the journey. The transport time between the slaughterhouse and the laboratory ranged from 1 to $2 \mathrm{~h}$. In the laboratory, ovaries were washed in the same solution with antibiotics used for transportation and were subsequently subjected to follicle puncture.

Ovarian follicles (3-8 $\mathrm{mm}$ ) were punctured and had their contents removed into a conical tube. The supernatant was decanted, and between 3 and $5 \mathrm{~mL}$ of a manipulation medium (TCM supplemented with Earle's salts, HEPES $25 \mathrm{mM}$, FCS 10\%, penicillin $100 \mathrm{IU} \mathrm{mL}^{-1}$, and streptomycin $100 \mathrm{mg} \mathrm{mL}^{-1}$ ) were added to the precipitate. The mixture was transferred to a Petri dish to search and retrieve COC, which were subsequently inspected and classified. Only COC with more than three compact layers of cumulus cells and homogeneous cytoplasm were used.

For in vitro maturation (IVM), the selected COC were washed in manipulation medium and then transferred to maturation medium (TCM 199 with Earle salts, with $10 \%$ of fetal calf serum, $20 \mu \mathrm{g} \mathrm{mL}^{-1}$ FSH, $100 \mathrm{mg} \mathrm{mL}^{-1}$ of streptomycin sulfate, and $100 \mathrm{IU} / \mathrm{mL}$ of penicillin). The COC were placed in petri dishes, containing 25-30 oocytes each and covered with mineral oil. The IVM was performed for $22 \mathrm{~h}$ in incubator at $38.5^{\circ} \mathrm{C}$ in $5 \% \mathrm{CO}_{2}$ with saturated humidity.

At the end of the maturation period, the oocytes were transferred to fertilization media. Oocytes were subjected to in vitro fertilization (IVF) with frozen semen from a single sample of a bull with proven fertility. Viable sperms were selected using the Mini-Percoll gradient technique. Briefly, the gradient was prepared transferring $400 \mu \mathrm{L}$ Percoll $90 \%$ to a microcentrifuge tube. On top of that, $400 \mu \mathrm{L}$ Percoll $45 \%$ was poured. Semen was carefully deposited at the top of the gradient in the tube, and the contents were centrifuged at $600 \times g$ for $15 \mathrm{~min}$. The supernatant was discarded, and the precipitate was resuspended in $1.0 \mathrm{~mL}$ SP-TALP medium. The second centrifugation was run at $600 \times g$ for $5 \mathrm{~min}$. The supernatant 
was discarded, and the precipitate was resuspended in $100 \mu \mathrm{L}$ fertilization medium prepared with TALP supplemented with $6 \mathrm{mg} \mathrm{mL}^{-1}$ fatty acid-free bovine serum albumin (BSA), $100 \mathrm{IU} \mathrm{mL}^{-1}$ penicillin, $100 \mu \mathrm{g} \mathrm{mL}^{-1}$ streptomycin, $2 \mathrm{mM}$ penicillamine, $1 \mathrm{mM}$ hypotaurine, $25 \mathrm{mM}$ epinephrine, and $0.2 \mathrm{mM}$ sodium pyruvate.

Mature COC were washed twice in FERT-TALP medium (Nutricell ${ }^{\circledR}$ ) and transferred to $100-\mu$ L fertilization microdroplets under mineral oil containing semen diluted to a concentration that generated a $2 \times 10^{6}$ sperms $\mathrm{mL}^{-1}$ fertilization dose. In vitro fertilization was carried out for $18 \mathrm{~h}$ in a $\mathrm{CO}_{2}$ incubator under the same IVM conditions.

After fertilization, viable zygotes were partly denuded, washed, and cultivated for seven days in synthetic oviductal fluid (SOF) containing FCS 5\% (Nutricell ${ }^{\circledR}$ ). Then, CLA (100 mM) was added in the first $72 \mathrm{~h}$ (CLA-F), last $72 \mathrm{~h}$ (CLA-L), and throughout the cultivation period (CLA-T). Control embryos were cultivated with no CLA. In vitro cultivation was carried out using 20 COC per $100-\mu \mathrm{L}$ microdroplet under mineral oil in an incubator at $38.5{ }^{\circ} \mathrm{C}$ with $5 \% \mathrm{CO}_{2}$ atmosphere and humidity saturation. Cleavage and blastocyst formation rates were analyzed 48 and $168 \mathrm{~h}$ after fertilization, respectively.

Embryos were cryopreserved by vitrification (Vajta et al., 1997). Initially, embryos were placed in maintenance medium (TCM 199 HEPES, FCS 20\%) for 1 min. Then, they were transferred to equilibrium solution (SV1) composed of ethylene glycol 10\% (EG) and dimethyl sulfoxide 10\% (DMSO) diluted in the maintenance medium described, where they remained for $3 \mathrm{~min}$. Next, embryos were placed in the vitrification solution (EG 20\%, DMSO 20\%) diluted in described maintenance medium for $30 \mathrm{~s}$.

During vitrification, embryos were loaded in open pulled straws (OPS, $\mathrm{N}=$ three embryos per straw) and immediately immersed in liquid nitrogen.

Devitrification was carried out by placing the narrow end of the OPS in the devitrification solution (maintenance solution, saccharose $0.3 \mathrm{M}$ ). Embryos were removed from the medium and immediately transferred to a well containing the same solution, where they were kept for $5 \mathrm{~min}$. Then, embryos were transferred to yet another well containing a devitrification solution formed by the maintenance solution and saccharose $1.5 \mathrm{M}$, where they remained for another $5 \mathrm{~min}$. Lastly, embryos were transferred to maintenance solution. All vitrification and devitrification solutions were maintained at $39^{\circ} \mathrm{C}$, and procedures were carried out at the same temperature.

Devitrified embryos were cultivated in commercial SOF containing FCS 5\% (Nutricell ${ }^{\circledR}$ ) for $48 \mathrm{~h}$. Survival rate was assessed $24 \mathrm{~h}$ after the beginning of cultivation. Blastocele reexpansion or hatching were the criteria used to consider an embryo viable. Hatching rate was assessed $48 \mathrm{~h}$ into cultivation and included all hatched embryos during the cultivation period.

Lipid contents of embryos were quantified using the Nile Red technique (Batista et al., 2014) with slight modifications. Oocytes and embryos ( $\mathrm{N}=68$, between 10 and 14 per treatment) were fixed in phosphate buffered saline (PBS) containing formalin $10 \%$ and polyvinyl alcohol $(0.01 \%)$. Oocytes and embryos were then transferred to a 500- $\mu$ L PBS microdroplet containing Nile Red $1 \mu \mathrm{g} \mathrm{mL}^{-1}$ (Sigma $\mathrm{N}-3013$ ) and kept overnight under these conditions. Next, the material was washed twice in PBS and mounted on a slide with glycerol and topped with a coverslip. All solutions used were stored in a dark environment, and analyses were carried out protected from light. Slides were inspected in an epifluorescence microscope (Eclipse TE 300, Nikon) to induce excitation of the dye and render visible the lipid contents of embryos. Each embryo was photographed using a specific digital camera (Nikon DS Ri1) coupled to the microscope. Images were analyzed using the NIS-AR software version 3.1 (Nikon).

In addition to embryos, oocytes at the germinal vesicle stage (GV, fixed immediately after follicle puncture) and maturated oocytes (MII, $22 \mathrm{~h}$ after in vitro maturation) were analyzed.

Lipid content of each embryo and of oocytes (GV and MII) treated with CLA at different times of cultivation (CLA-F, CLA-L, CLA-T, and control) were assessed using the specific software platform, according to which the higher the fluorescence, the higher the lipid content of a sample. Image pixels of embryos or oocytes were used to quantify the emission of fluorescence and scored 0 to 255 arbitrary 
fluorescence units (AFU). Data were exported to Excel spreadsheets (Microsoft ${ }^{\circledR}, 2010$ ) for subsequent statistical analysis.

The data obtained were analyzed in the R environment (version 2.11.1). The statistical model used was:

$$
\mathrm{Y}_{\mathrm{ij}}=\mu+\mathrm{t}_{\mathrm{i}}+\mathrm{e}_{\mathrm{ij}}
$$

in which $Y_{i j}=$ value observed in the experimental unit $i$ for repeat $j, \mu=$ general mean, $t_{i}=$ effect of treatment $\mathrm{i}$, and $\mathrm{e}_{\mathrm{ij}}=$ residual error.

The experiment was carried out seven times (repeats), and each repeat was considered the experimental unit, from which cleavage rate, blastocyst rate, hatching rate, and lipid content were obtained for the different treatments.

Normality of data was assessed using the Kolmogorov-Smirnov test and data that did not fit the normal distribution (lipid content) were analyzed using the non-parametric Kruskal-Wallis test with multiple comparison of means. Cleavage rate, embryo yield, survival rate, and hatching rate data were evaluated using an analysis of variance. Means that differed statistically were analyzed using the Tukey test. The level of significance used in all analyses was $5 \%$.

\section{Results}

In total, 974 oocytes were used to assess the effect of CLA at different moments into cultivation. No statistically significant differences $(\mathrm{P}>0.05)$ were observed between treatments, whether in cleavage rate, or blastocyst:total oocyte and blastocyct:cleaved oocyte ratios (Table 1).

The fluorescence labeling of lipids carried out using Nile Red showed that CLA-T embryos had the lowest lipid content, with values that were similar to those observed for GV oocytes. In other words, these structures were not affected by the settings of the in vitro cultivation medium. Oppositely, embryos cultivated with CLA-F and CLA-L had higher lipid content than control embryos and MII oocytes (Figures 1 and 2).

Cryoresistance was assessed using 246 vitrified embryos that were randomly assigned to treatments. Embryos in CLA-L had a significantly lower $(\mathrm{P}<0.05)$ survival rate $24 \mathrm{~h}$ after vitrification compared with CLA-F and CLA-T, although with no statistically significant difference compared with control $(\mathrm{P}>0.05)$. However, treatment with CLA-T improved hatching rate of embryos $(\mathrm{P}<0.05)$ (Table 2).

\section{Discussion}

Gardner and Wale (2013) verified that glucose metabolism is abnormal in in vitro-produced embryos. According to Bavister (1995), this change is defined as "Crabtree effect", which is characterized by an increase in the metabolism of glucose via glycolysis with inhibition of oxidative phosphorylation. This author also mentions that this effect is not observed in in vivo-produced embryos because, possibly in the physiological environment, there would exist a natural glycolysis inhibitor.

Table 1 - Effect of CLA on cleavage rate and blastocyst yield of bovine embryos cultivated in vitro

\begin{tabular}{lcccc}
\hline Treatment & \multicolumn{3}{c}{ Embryo yield } \\
\cline { 2 - 5 } & $\begin{array}{c}\text { Oocytes } \\
(\mathrm{n})\end{array}$ & $\begin{array}{c}\text { Cleavage } \\
(\% \pm \text { SEM) }\end{array}$ & $\begin{array}{c}\text { Blastocysts:oocytes } \\
(\% \pm \text { SEM) }\end{array}$ & $\begin{array}{c}\text { Blastocysts:Cleaved oocyte } \\
(\% \pm \text { SEM) }\end{array}$ \\
\hline Control & 229 & $67.6 \pm 1.7$ & $33.1 \pm 5.0$ & $48.9 \pm 7.5$ \\
CLA-F & 250 & $62.8 \pm 4.9$ & $25.6 \pm 3.5$ & $40.0 \pm 3.1$ \\
CLA-L & 247 & $60.8 \pm 4.8$ & $25.9 \pm 4.6$ & $43.7 \pm 8.8$ \\
CLA-T & 248 & $60.7 \pm 4.2$ & $32.5 \pm 8.3$ & $57.5 \pm 16.9$ \\
\hline
\end{tabular}

SEM - standard error of the mean.

${ }^{1}$ Control: with no CLA; CLA-F: CLA added in the first $72 \mathrm{~h}$; CLA-L: CLA added in the last $72 \mathrm{~h}$; CLA-T: CLA added throughout cultivation. 
The highest activation of the glycolysis pathway, caused by the Crabtree effect, could generate an accumulation of lipids due to the increase in the concentration of fatty acids precursors, such as acetyl-CoA (Rieger et al., 2002). These findings, added to the results of Abe et al. (2002), who observed that the highest lipid content in in vitro embryos cultivated in medium with FCS are observed between the 8-cell stage and the morula stage, prompted us to assess the effect of CLA added at different moments into cultivation, namely before and after compaction. In the present study, no statistically

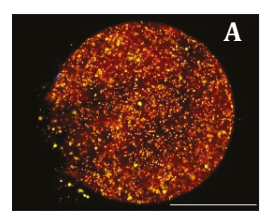

$\mathbf{A}^{\prime}$
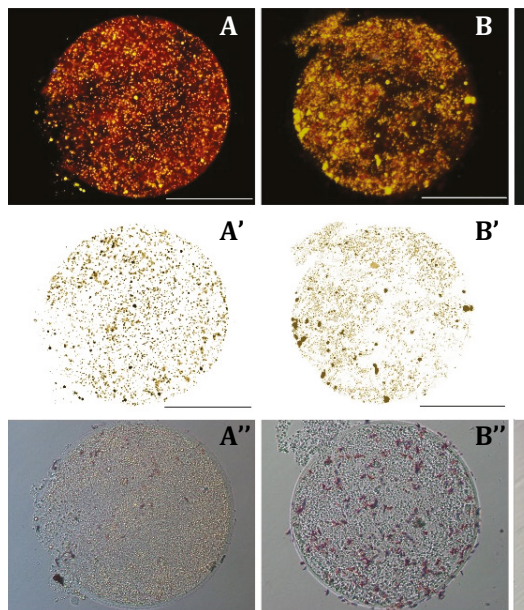

B'
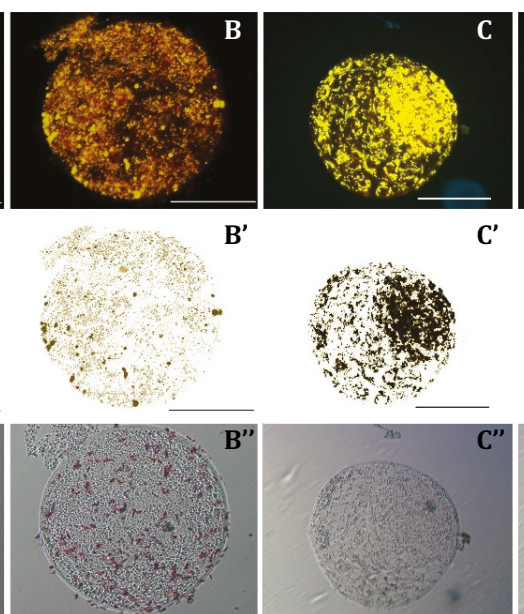

$\mathbf{C}^{\prime}$
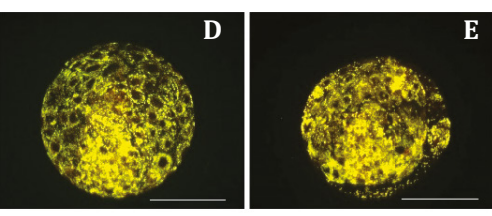

D'
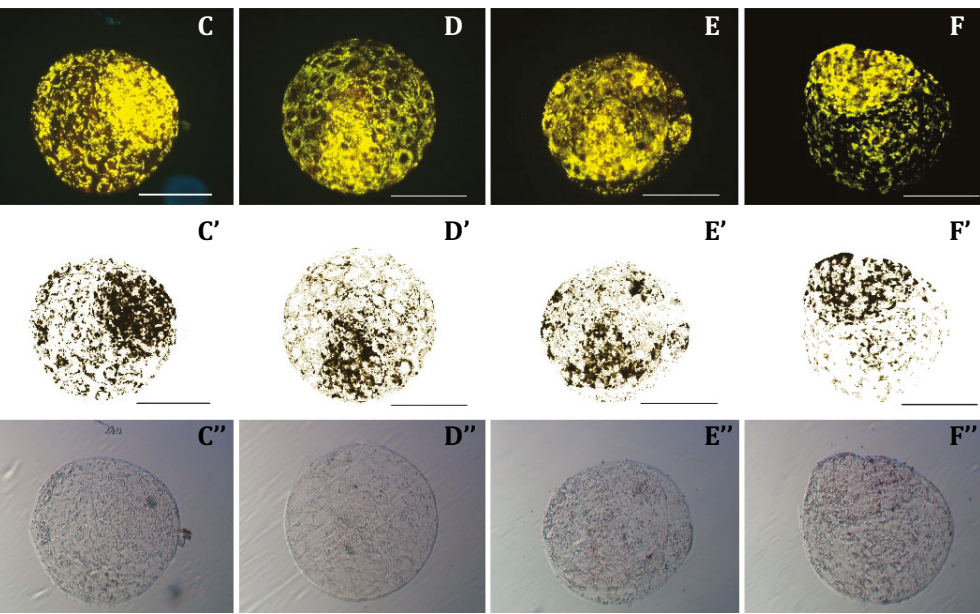
$\mathbf{F}^{\prime}$

In A to $\mathrm{F}$, the labeling used to quantify lipids based on arbitrary fluorescence units; in $\mathrm{A}^{\prime}$ to $\mathrm{F}^{\prime}$, the inversion of the contrast of the first sequence of images to highlight staining and indicate the location, distribution, and size of lipid microdroplets; in A" to F", structures in bright field. Bars: $50 \mu \mathrm{m}$; all images were recorded at $400 \mathrm{X}$ magnification.

Figure 1 - Fluorescence labeling by Nile Red of lipid contents of oocytes at the germinal vesicle stage (VG; A), oocytes maturated for $22 \mathrm{~h}$ (MII; B), and embryos cultivated with no CLA (control; C) in the first $72 \mathrm{~h}$ of cultivation (CLA-F; D), last $72 \mathrm{~h}$ of cultivation (CLA-L; E), and throughout cultivation (CLA-T; F).

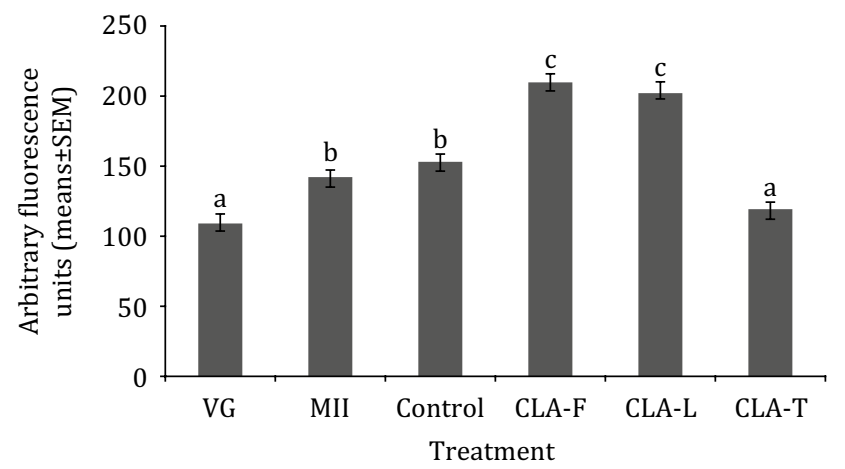

SEM - standard error of the mean.

Figure 2 - Lipid contents of oocytes at the germinal vesicle stage (VG), oocytes maturated for $22 \mathrm{~h}$ (MII), embryos cultivated with no CLA (control), embryos cultivated with CLA in the first $72 \mathrm{~h}$ of cultivation (CLA-F), last $72 \mathrm{~h}$ of cultivation (CLA-L), and throughout cultivation (CLA-T).

Table 2 - Reexpansion and hatching rates ${ }^{1}$ of the embryos cultivated in vitro

\begin{tabular}{lccc}
\hline Treatment $^{2}$ & $\mathrm{~N}$ & $\begin{array}{c}\text { Reexpansion } \\
(\% \pm \text { SEM) }\end{array}$ & $\begin{array}{c}\text { Hatching } \\
(\% \pm \text { SEM) }\end{array}$ \\
\hline Control & 65 & $50.3 \pm 3.5 \mathrm{ab}$ & $26.0 \pm 8.6 \mathrm{a}$ \\
CLA-F & 67 & $60.6 \pm 4.6 \mathrm{~b}$ & $33.7 \pm 4.3 \mathrm{a}$ \\
CLA-L & 64 & $40.0 \pm 8.2 \mathrm{a}$ & $22.6 \pm 3.4 \mathrm{a}$ \\
CLA-T & 68 & $61.8 \pm 3.2 \mathrm{~b}$ & $61.8 \pm 3.2 \mathrm{~b}$ \\
\hline
\end{tabular}

SEM - standard error of the mean.

${ }^{1}$ Reexpansion and hatching rates were measured $24 \mathrm{~h}$ and $48 \mathrm{~h}$ after devitrification.

${ }^{2}$ Control: with no CLA; CLA-F: CLA added in the first $72 \mathrm{~h}$; CLA-L: CLA added in the last $72 \mathrm{~h}$; CLA-T: CLA added throughout cultivation 
significant difference was observed in embryo yields among treatments. On the other hand, the addition of CLA at different moments during embryo development showed that the compound affects lipid content and cryoresistance.

Embryo cleavage and yield did not differ significantly among treatments ( $\mathrm{P}>0.05$; Table 1$)$. These findings show that the CLA concentration used $(100 \mu \mathrm{M})$ did not have any toxic effect, since it improved cryoresistance with no decrease in embryo yield. Similar findings were obtained by Batista et al. (2014) and Pereira et al. (2007), who also used cultivation media supplemented with FCS and CLA $100 \mu \mathrm{M}$. Yet, Stinshoff et al. (2014) used a cultivation medium with no FCS and observed that the addition of CLA during in vitro cultivation reduced blastocyst yield. In another study, a decrease in blastocyst yield was recorded when parthenotes were cultivated in a CLA medium with no FCS (Absalón-Medina et al., 2014).

The positive effect of FCS has been demonstrated by various authors, who proved that FCS speeds up the embryo development rate upon the morula stage (Lazzari et al., 2002; Lequarre et al., 2003; Rizos et al., 2003). In addition, FCS has also been shown to increase the number of cells per embryo and induce a rise in percent number of embryos hatched (Holm et al., 2002; Lazzari et al., 2002; George et al., 2008; Sudano et al., 2011). Such advantageous properties of FCS may balance out the harmful effects of CLA on embryo yield as observed by Stinshoff et al. (2014) and Absalón-Medina et al. (2014), making lipid levels in in vitro embryos reach similar values as those observed for in vivo embryos.

The addition of CLA to in vitro culture media at different times of cultivation influenced lipid content of embryos, independently of whether the compound was added in the beginning, end, or throughout the cultivation period. Surprisingly, embryos treated with CLA-F and CLA-L had higher lipid contents compared with the control. However, the embryos treated with CLA-T had lower levels of lipids, compared with the other groups $(\mathrm{P}<0.05)$. This may be associated with the change in gene expression pattern of enzymes with a role in lipid metabolism (Lee et al., 1998). It may be hypothesized that the effect of CLA on the downregulation of lipogenic enzymes requires the incorporation of the compound, which means that embryos have to be exposed to CLA for relatively long periods. Or even, that the effect of CLA would be observed only when this component is present during the period of maternal zygote transition, between 72 and $96 \mathrm{~h}$ of culture.

Thus, lipid accumulation at levels similar to the control group observed in the CLA-F and CLA-L treatments may have occurred due to the absence of CLA throughout the maternal zygote transition period.

Such results show that CLA needs to be present in the cultivation medium throughout the cultivation process for lipid content to decrease and cryoresistance to increase, which corroborates the idea that CLA must be present throughout the maternal zygote transition period for its effect to be observed. Unfortunately, however, the specific transition period was not assessed in isolation.

In the present study, lipid levels in embryos were similar to the values observed for oocytes that were not subjected to any influence of the in vitro conditions (that is, GV oocytes; P>0.05). Recently, Collado et al. (2017) observed that oocytes maturated in vitro had significantly high levels of lipids compared with oocytes maturated in vivo. The data obtained by the authors suggested that lipid content in oocytes could be the result of the transport of fatty acids produced by COC, which presented changes in the expression of genes that regulate lipid content. This was not observed for oocytes. Besides, these findings may explain, at least in part, the increase in lipid levels in MII oocytes (after in vitro maturation) compared with GV oocytes (with no influence of in vitro production) (Figure 2).

Baumgard et al. (2002) described the decrease in lipogenic enzyme transcripts in mammary tissue of lactating cows after administration of an intramammary infusion of a CLA solution. The consequence of this reduction in gene expression was low lipid-level milk. Conjugated linoleic acid also affected the expression of enzymes with a role in lipid metabolism in embryos, among which stearoyl-CoA desaturase (SCD1) and fatty acid desaturase 2 (FADS2) (Al Darwich et al., 2010).

Nagashima et al. (1995) used pig embryos to demonstrate, for the first time, that a decrease in lipid levels induces an increase in cryoresistance. After that pioneering study, numerous investigations 
have been carried out confirming these results also for bovines (Rizos et al., 2003; Seidel Jr., 2006; Pereira et al., 2007; Pereira et al., 2008; Barceló-Fimbres and Seidel Jr., 2011; Sudano, 2011).

Similarly to the previous results discussed above, the findings obtained in the present study confirm that embryos treated with CLA-T had also the lowest lipid content, showing that CLA may be a useful additive to improve cryoresistance of bovine embryos, mainly in in vitro production systems that still use media containing FCS. These results corroborate the findings published by Pereira et al. (2007), who demonstrated, for the first time, that supplementation of embryo culture media with CLA reduces lipid content in embryos and increases cryoresistance.

The beneficial effect of CLA on cryoresistance may also be explained in view of the increase in cytoplasmic membrane fluidity. Leão et al. (2015) observed that CLA changes the lipid profile of the cytoplasmic membrane, a phenomenon that had been previously hypothesized by Hochi et al. (1999). Moreover, CLA is able to change the fatty acid profile, influencing the levels of triglycerides or directly affecting the levels of saturated as well as unsaturated fatty acids, possibly by inhibiting the expression of genes that code for the synthesis of lipogenic enzymes and the activity of lipoprotein lipase. This enzyme hydrolyzes triglycerides into lipoproteins; for this reason, inhibition of lipoprotein lipase increases the intracellular content of triglycerides (Park et al., 1997).

In another study, Al Darwich et al. (2010) evaluated the effect of different polyunsaturated fatty acids on the cultivation of bovine embryos, demonstrating that these fatty acids may reduce levels of FADS2 gene transcripts without affecting the levels of transcripts of other genes associated with lipid metabolism. Downregulation of FADS2 may induce the reduction of lipid content in embryos, since the enzyme catalyzes the biosynthesis of precursors used in the synthesis of polyunsaturated fatty acids.

\section{Conclusions}

Treatment of bovine embryos with conjugated linoleic acid during in vitro cultivation does not affect the yield of blastocysts, promoting the reduction of lipid levels and improving cryoresistance. Nevertheless, these effects only manifest when embryos are treated with conjugated linoleic acid throughout the cultivation period. Therefore, conjugated linoleic acid may be used as an additive to cultivation media for bovine embryos as a means to increase cryoresistance in production systems that use fetal calf serum.

\section{Conflict of Interest}

The authors declare no conflict of interest.

\section{Author Contributions}

Conceptualization: B.P. Carvalho and A.J.B. Dias. Data curation: B.P. Carvalho and D. Detoni. Formal analysis: B.P. Carvalho and F.Q. Costa. Funding acquisition: A.J.B. Dias. Investigation: B.P. Carvalho and F.Q. Costa. Methodology: B.P. Carvalho, F.Q. Costa, D. Detoni, F.B. Rosa and A.J.B. Dias. Project administration: A.J.B. Dias. Visualization: F.Q. Costa. Writing-original draft: B.P. Carvalho and A.J.B. Dias. Writing-review \& editing: B.P. Carvalho and A.J.B. Dias.

\section{References}

Abe, H.; Yamashita, S.; Satoh, T. and Hoshi, H. 2002. Accumulation of cytoplasmic lipid droplets in bovine embryos and cryotolerance of embryos developed in different culture systems using serum-free or serum containing media. Molecular Reproduction and Development 61:57-66. https://doi.org/10.1002/mrd.1131

Absalón-Medina, V. A.; Bedford-Guaus, S. J.; Gilbert, R. O.; Siqueira, L. C.; Esposito, G.; Schneider, A.; Cheong, S. H. and Butler, W. R. 2014. The effects of conjugated linoleic acid isomers cis-9,trans-11 and trans-10,cis-12 on in vitro bovine embryo production and cryopreservation. Journal of Dairy Science 97:6164-6176. https://doi.org/10.3168/jds.2013-7719 
Al Darwich, A.; Perreau, C. P.; Petit, M. H.; Papillier, P.; Dupont, J.; Guillaume, D.; Mermillod, P. and Guignot, F. 2010. Effect of PUFA on embryo cryoresistance, gene expression and AMPK $\alpha$ phosphorylation in IVF derived bovine embryos. Prostaglandins \& Other Lipid Mediators 93:30-36. https://doi.org/10.1016/j.prostaglandins.2010.06.002

Barceló-Fimbres, M. and Seidel Jr., G. E. 2011. Cross-validation of techniques for measuring lipid content of bovine oocytes and blastocysts. Theriogenology 75:434-444. https://doi.org/10.1016/j.theriogenology.2010.09.007

Barceló-Fimbres, M. and Seidel Jr., G. E. 2007. Effects of either glucose or fructose and metabolic regulators on bovine embryo development and lipid accumulation in vitro. Molecular Reproduction and Development 74:1406-1418. https://doi.org/10.1002/mrd.20700

Batista, R. I. T. P.; Raposo, N. R. B.; Campos-Junior, P. H. A.; Pereira, M. M.; Camargo, L. S. A.; Carvalho, B. C.; Gama, M. A. S. and Viana, J. H. M. 2014. Trans-10, cis-12 conjugated linoleic acid reduces neutral lipid content and may affect cryotolerance of in vitro-produced crossbred bovine embryos. Journal of Animal Science and Biotechnology 5:33. https://doi.org/10.1186/2049-1891-5-33

Baumgard, L. H.; Matitashvili, E.; Corl, B. A.; Dwyer, D. A. and Bauman, D. E. 2002. Trans-10, cis-12 conjugated linoleic acid decreases lipogenic rates and expression of genes involved in milk lipid synthesis in dairy cows. Journal of Dairy Science 85:2155-2163. https://doi.org/10.3168/jds.S0022-0302(02)74294-X

Bavister, B. D. 1995. Culture of preimplantation embryos: facts and artifacts. Human Reproduction Update 1:91-148. https://doi.org/10.1093/humupd/1.2.91

Collado, M. D.; Silveira, J. C.; Sangalli, J. R.; Andrade, G. M.; Sousa, L. R. S.; Silva, L. A.; Meirelles, F. and Perecin, F. 2017. Fatty acid binding protein 3 and transzonal projections are involved in lipid accumulation during in vitro maturation of bovine oocytes. Scientific Reports 7:2645. https://doi.org/10.1038/s41598-017-02467-9

Gardner, D. K. and Wale, P. L. 2013. Analysis of metabolism to select viable human embryos for transfer. Fertility and Sterility 99:1062-1072. https://doi.org/10.1016/j.fertnstert.2012.12.004

George, F.; Daniaux, C.; Genicot, G.; Verhaeghe, B.; Lambert, P. and Donnay, I. 2008. Set up of a serum-free culture system for bovine embryos: Embryo development and quality before and after transient transfer. Theriogenology 69:612-623. https://doi.org/10.1016/j.theriogenology.2007.11.008

Hochi, S.; Kimura, K. and Hanada, A. 1999. Effect of linoleic acid-albumin in the culture medium on freezing sensitivity of in vitro-produced bovine morulae. Theriogenology 52:497-504. https://doi.org/10.1016/S0093-691X(99)00146-6

Holm, P.; Booth, P. J. and Callesen, H. 2002. Kinetics of early in vitro development of bovine in vivo and in vitro derived zygotes produced and/or cultured in chemically defined or serum containing media. Reproduction 123:553-565. https://doi.org/10.1530/rep.0.1230553

Khurana, N. K. and Niemann, H. 2000. Energy metabolism in preimplantation bovine embryos derived in vitro or in vivo. Biology of Reproduction 62:847-856. https://doi.org/10.1095/biolreprod62.4.847

Lapa, M.; Marques, C. C.; Alves, S. P.; Vasques, M. I.; Baptista, M. C.; Carvalhais, I.; Silva Pereira, M.; Horta, A. E. M.; Bessa, R. J. B. and Pereira, R. M. 2011. Effect of trans-10 cis-12 conjugated linoleic acid on bovine oocyte competence and fatty acid composition. Reproduction in Domestic Animals 46:904-910. https://doi.org/10.1111/j.1439-0531.2011.01762.x

Lazzari, G.; Wrenzycki, C.; Herrmann, D.; Duchi, R.; Kruip, T.; Niemann, H. and Galli, C. 2002. Cellular and molecular deviations in bovine in vitro-produced embryos are related to the large offspring syndrome. Biology of Reproduction 67:767-775. https://doi.org/10.1095/biolreprod.102.004481

Leão, B. C. S.; Rocha-Frigoni, N. A. S.; Cabral, E. C.; Coelho, M. B.; Ferreira, C. R.; Eberlin, M. N.; Accorsi, M. F.; Nogueira, E. and Mingoti, G. Z. 2015. Improved embryonic cryosurvival observed after in vitro supplementation with conjugated linoleic acid is related to changes in the membrane lipid profile. Theriogenology 84:127-136. https://doi.org/10.1016/j. theriogenology.2015.02.023

Lee, K. N.; Pariza, M. W. and Ntambi, J. M. 1998. Conjugated linoleic acid decreases hepatic stearoyl-CoA desaturase mRNA expression. Biochemical and Biophysical Research Communications 248:817-821. https://doi.org/10.1006/ bbrc.1998.8994

Leidenfrost, S.; Boelhauve, M.; Reichenbach, M.; Güngör, T.; Reichenbach, H.-D.; Sinowatz, F.; Wolf, E. and Habermann, F. A. 2011. Cell arrest and cell death in mammalian preimplantation development: Lessons from the bovine model. PLoS ONE 6:e22121. https://doi.org/10.1371/journal.pone.0022121

Lequarre, A. S.; Marchandise, J.; Moreau, B.; Massip, A. and Donnay, I. 2003. Cell cycle duration at the time of maternal zygotic transition for in vitro-produced bovine embryos: effect of oxygen tension and transcription inhibition. Biology of Reproduction 69:1707-1713. https://doi.org/10.1095/biolreprod.103.017178

Nagashima, H.; Kashiwazaki, N.; Ashman, R. J.; Grupen, C. G. and Nottle, M. B. 1995. Cryopreservation of porcine embryos. Nature 374:416. https://doi.org/10.1038/374416a0

Park, S. E.; Son, W. Y.; Lee, K. A.; Ko, J. J. and Cha, K. Y. 1997. Chromosome and spindle configurations of human oocytes matured in vitro after cryopreservation at the germinal vesicle stage. Fertility and Sterility 68:920-926. https://doi.org/10.1016/s0015-0282(97)00365-8

R. Bras. Zootec., 48:e20180322, 2019 
Pereira, R. M.; Carvalhais, I.; Pimenta, J.; Baptista, M. C.; Vasques, M. I.; Horta, A. E. M.; Santos, I. C.; Marques, M. R.; Reis, A.; Pereira, M. S. and Marques, C. C. 2008. Biopsied and vitrified bovine embryos viability is improved by trans 10 , cis 12 conjugated linoleic acid supplementation during in vitro embryo culture. Animal Reproduction Science 106:322-332. https://doi.org/10.1016/j.anireprosci.2007.05.008

Pereira, R. M.; Baptista, M. C.; Vasques, M. I.; Horta, A. E. M.; Portugal, P. V.; Bessa, R. J. B.; Chagas e Silva, J.; Pereira, M. S. and Marques, C. C. 2007. Cryosurvival of bovine blastocysts is enhanced by culture with trans-10 cis-12 conjugated linoleic acid (10t,12c CLA). Animal Reproduction Science 98:293-301. https://doi.org/10.1016/j.anireprosci.2006.03.015

Pontes, J. H. F.; Melo Sterza, F. A.; Basso, A. C.; Ferreira, C. R.; Sanches, B. V.; Rubin, K. C. P. and Seneda, M. M. 2011. Ovum pick up, in vitro embryo production, and pregnancy rates from a large-scale commercial program using Nelore cattle (Bos indicus) donors. Theriogenology 75:1640-1646. https://doi.org/10.1016/j.theriogenology.2010.12.026

Rieger, D.; McGrowan, L. T.; Cox, S. F.; Pugh, P. A. and Thompson, J. G. 2002. Effect of 2,4-dinitrophenol on the energy metabolism of cattle embryos produced by in vitro fertilization and culture. Reproduction Fertility and Development 14:339-343. https://doi.org/10.1071/RD02038

Rizos, D.; Gutiérrez-Adán, A.; Pérez-Garnelo, S.; De La Fuente, J.; Boland, M. P. and Lonergan, P. 2003. Bovine embryo culture in the presence or absence of serum: implications for blastocyst development, cryotolerance, and messenger RNA expression. Biology of Reproduction 68:236-243. https://doi.org/10.1095/biolreprod.102.007799

Seidel Jr., G. E. 2006. Modifying oocytes and embryos to improve their cryopreservation. Theriogenology 65:228-235. https://doi.org/10.1016/j.theriogenology.2005.09.025

Stinshoff, H.; Wilkening, S.; Hanstedt, A.; Bollwein, H. and Wrenzycki, C. 2014. Dimethylsulfoxide and conjugated linoleic acids affect bovine embryo development in vitro. Reproduction, Fertility and Development 26:502-510. https://doi.org/10.1071/RD12372

Sudano, M. J.; Paschoal, D. M.; Rascado, T. S.; Magalhães, L. C. O.; Crocomo, L. F.; Lima-Neto, J. F. and Landim-Alvarenga, F. C. 2011. Lipid content and apoptosis of in vitro-produced bovine embryos as determinants of susceptibility to vitrification. Theriogenology 75:1211-1220. https://doi.org/10.1016/j.theriogenology.2010.11.033

Vajta, G.; Booth, P. J.; Holm, P.; Greve, T. and Callesen, H. 1997. Successful vitrification of early stage bovine in vitro produced embryos with the open pulled straw (OPS) method. Cryo Letters 18:191-195.

Wrenzycki, C. 2016. In vitro culture systems: how far are we from optimal conditions? Animal Reproduction 13:279-282. https://doi.org/10.21451/1984-3143-AR869 